\title{
Effect of puerarin on collagen metabolism of fibroblasts in pelvic tissue of women with pelvic organ prolapse
}

\author{
YANG LI, LI HONG, CHENG LIU, JIE MIN, SHASHA HONG, MING HU, \\ YANG ZHAO, QING YANG, JIANMING TANG and SONGMING HE
}

\begin{abstract}
Department of Gynecology and Obstetrics, Renmin Hospital of Wuhan University, Wuhan, Hubei 430060, P.R. China
\end{abstract}
Received February 2, 2016; Accepted February 20, 2017

DOI: $10.3892 / \mathrm{mmr} .2017 .8112$

\begin{abstract}
The aim of the present study was to investigate the protective effect of puerarin on pelvic organ prolapse (POP) and the underlying mechanisms that regulate the metabolism of human parametrial ligament fibroblasts (HPLFs). HPLFs obtained from the pelvic tissue of patients with $(n=10)$ or without $(n=8)$ POP during hysterectomy were isolated by enzymatic digestion and subsequently identified by immunocytochemistry in a previous study of the authors. Following this, cultured HPLFs were treated with $0.01,0.10$ or $1.00 \mathrm{mmol} / \mathrm{l}$ puerarin, followed by detection of proliferation rate by Cell Counting kit-8 assay. Following incubation with puerarin for $48 \mathrm{~h}$, mRNA and protein expression levels of tissue inhibitor of metalloproteinase-1 (TIMP-1), matrix metalloproteinase (MMP)-2 and -9 , and collagen (COL)I and III in HPLFs were quantified by reverse transcription-quantitative polymerase chain reaction, and western blot and gelatin zymography analyses, respectively. MMP-2 and -9 expression levels were increased, whereas expression levels of TIMP-1, and COL I and III were decreased, in patients with POP compared with healthy controls. Following puerarin treatment, the expression levels of TIMP-1, and COL I and III were enhanced, whereas MMP-2 and -9 were inhibited. In conclusion, the present study demonstrated evidence increased degradation of the extracellular matrix in pelvic tissues of patients with POP compared with controls, and the protective effect of puerarin against POP via its anti-degradation effect on collagen. These results provide evidence for puerarin as a novel approach for the treatment of POP.
\end{abstract}

\section{Introduction}

Pelvic organ prolapse (POP) refers to a collection of conditions whereby the uterine, anterior vaginal wall and/or posterior

Correspondence to: Dr Li Hong, Department of Gynecology and Obstetrics, Renmin Hospital of Wuhan University, 238 Jiefang Road, Wuhan, Hubei 430060, P.R. China

E-mail: 510158841@qq.com

Key words: pelvic organ prolapse, puerarin, fibroblast, collagen, traditional Chinese medicine vaginal wall prolapses. POP incidence is more common in middle-aged and elderly females, with a worldwide frequency of $\sim 37 \%$ in women who have experienced vaginal birth delivery (1), and may result in physical and psychological harm to patients, seriously decreasing their quality of life. Epidemiological studies have revealed well-established risk factors of the disease including birth delivery injury, obesity, chronic increased abdominal pressure and age (2). Currently, the treatment of POP is dominated by surgical repair of the native tissue with vaginal meshes, which typically has positive outcomes. The use of meshes, however, is associated with considerable risk of erosion, pain, infection and vaginal stenosis. In addition, the curative effect of drug therapy, a therapeutic method for patients with mild POP, remains unclear. Therefore, the establishment of effective treatments and prevention methods are required for patients with POP.

Kudzu root, a Chinese herb containing puerarin (7,4-dihydroxy-8- $\beta$-D-glucosylisoflavone, $\mathrm{C}_{21} \mathrm{H}_{20} \mathrm{O}_{9}$ ) as its main isoflavone glycoside, has been used for thousands of years in traditional Chinese medicine for the treatment of fever, diarrhea, cardiovascular diseases and diabetes in (3), and has been previously been used for its antioxidant (4), anti-hyperglycemic (5) and anti-inflammatory (6) properties. Additionally, its influence on proliferation and differentiation of osteoblasts has been demonstrated (7).

It has been reported that estrogen may significantly increase the ratio of collagen (COL)I/III in urethral and anal vasculature of young adult rats (8), and its function of increasing the rate of fibroblast proliferation has also been reported (9). The association between intrinsic connective tissue abnormality and the development of POP is widely understood (10). HoxAl1 is essential for the formation of uterosacral ligaments, which supports the vaginal wall in mice (11). Furthermore, as a phytoestrogen, puerarin has been demonstrated to affect loss of bone density in ovariectomized mice (12). Puerarin may also induce inflammation in mouse mesangial cells associated with the production of matrix metalloproteinase (MMP)-2 and -9 during advanced glycation, and $\mathrm{N}$-carboxymethyllysine (13). The increased invasiveness of endometriotic stromal cells by vimentin E2 may be significantly reversed by puerarin by increasing MMP-9 accumulation and decreasing tissue inhibitor of metalloproteinase (TIMP)-1 accumulation (14).

In addition, under certain conditions including inflammation and endometriosis, the expression of MMP-2 and 
-9 are inhibited by puerarin, and the expression of TIMP-1 increased $(15,16)$. Furthermore, puerarin has been studied for its wide-ranging effects on angiogenesis (17). It has been demonstrated that administration of puerarin reduces spinal ischemia-reperfusion injury by exerting neuroprotective properties (18). Incubation of isolated human mononuclear cells with 0.1-3 mmol/l puerarin may increase the number of endothelial progenitor cells, and enhance proliferation, migration, adhesion and in vitro vasculogenesis $(7,19)$.

Therefore, it was hypothesized that puerarin may inhibit POP by regulating the metabolism of fibroblasts. To verify this, an in vitro cell culture was established to evaluate the potential effects of puerarin against POP and the underlying mechanisms involved, which may provide a novel pharmacological therapeutic approach for the treatment of POP.

\section{Materials and methods}

Ethics statement. Human protocols were approved by the Ethics Committee of Renmin Hospital of Wuhan University (Wuhan, China). All samples were obtained from patients undergoing routine hysterectomy following obtaining signed informed consent forms.

Patients. A total of 8 patients who underwent hysterectomy surgery for reasons excluding the presence of malignant tumors and POP, served as controls, and 10 patients who underwent hysterectomy surgery only for POP (POP-Q standard: POP-IV) in the Obstetric and Gynecological Department of Renmin Hospital of Wuhan University, were enrolled in the present study. None of these recruited women had any connective tissue diseases, pathologically confirmed endometriosis or estrogen-associated ovarian tumors. Furthermore, these patients were free from any complications that may lead to collagen depleted-associated diseases, including diabetes and hyperthyroidism. Patients who had received surgery in the uterosacral ligamental site ever or had a history of estrogen application within the past three months were excluded from the present study.

Primary cell culture. A modified enzyme digestion method was used in the present study for the establishment of primary cell culture. Tissue specimens $\left(0.5 \times 0.5 \times 0.2 \mathrm{~cm}^{3}\right)$ were dissected from part of the parametrial ligament (including sacral and associated ligaments) during surgery. The tissues were washed with phosphate-buffered saline (HyClone; GE Healthcare Life Sciences, Logan, UT, USA) containing $1 \%$ antibiotics $(100 \mathrm{KU} / \mathrm{ml}$ penicillin $\mathrm{G}$ and $100 \mathrm{mg} / \mathrm{ml}$ streptomycin; Hangzhou Ginom Biomedical Technology Co., Ltd., Hangzhou, China) 3-5 times to clear the underlying blood, axungia and necrotic tissue, following which tissues were sectioned into $\sim 1 \mathrm{~mm}^{3}$ thick pieces. Sections were digested with $1 \%$ collagenase-I (Invitrogen; Thermo Fisher Scientific, Inc., Waltham, MA, USA) for $3 \mathrm{~h}$ at $37^{\circ} \mathrm{C}$ in $5 \% \mathrm{CO}_{2}$, followed by further digestion with $0.25 \%$ trypsin (Sigma-Aldrich; Merck KGaA, Darmstadt, Germany) for $5 \mathrm{~min}$. Subsequently, $2 \mathrm{ml}$ fetal bovine serum (FBS; Gibco; Thermo Fisher Scientific, Inc.) was added to halt digestion. Dulbecco's Modified Eagle's medium (DMEM; Hangzhou Ginom Biomedical Technology Co., Ltd.) supplemented with $15 \%$ FBS was slowly added to the culture bottle. The culture medium was replaced every two days and human parametrial ligament fibroblasts (HPLFs) were cultured to $70 \%$ confluence for passage. The stable primary cells were obtained after $\sim 15$ days. The HPLFs were used at passage 4-8 for subsequent experiments.

Cell viability assay. HPLF viability following treatment with puerarin was detected using Cell Counting Kit-8 (CCK-8; Dojindo Molecular Technologies, Inc., Shanghai, China). Cells at a density of $\sim 3 \times 10^{3}$ were seeded into a 96-well plate containing $100 \mu 1$ DMEM. Cells were treated with $0.01,0.1$ or $1.0 \mathrm{mmol} / \mathrm{l}$ puerarin for 24,48 or $72 \mathrm{~h}$, following which $100 \mu \mathrm{l}$ fresh medium containing $10 \mu$ l CCK-8 solution was added into each well and cells were incubated for $1 \mathrm{~h}$ at $37^{\circ} \mathrm{C}$. The optical density was measured at wavelength of $450 \mathrm{~nm}$ using a spectrophotometric plate reader. Each group was repeated in 5 wells.

Puerarin treatment of HPLFs. Puerarin was purchased from Chengdu Must Bio-technology Co., Ltd. (Changdu, China; purity, HPLC $\geq 98 \%$ ). Based on previous studies $(7,19-21)$ and the results of the CCK- 8 assay, the concentration of puerarin in the drug group was set at $0.01,0.1$ and $1 \mathrm{mmol} / 1$. Healthy passage 4 HPLFs were used in the drug experiments. Cells $\left(2 \times 10^{5} / \mathrm{ml}\right)$ were seeded into six-well plates and incubated for $24 \mathrm{~h}$ at $37^{\circ} \mathrm{C}$ in $5 \% \mathrm{CO}_{2}$. Following this, $1.5 \mathrm{ml}$ medium containing $0.01,0.1$ or $1 \mathrm{mmol} / 1$ was added to the each well, and HPLFs were incubated for $48 \mathrm{~h}$ at $37^{\circ} \mathrm{C}$ in $5 \% \mathrm{CO}_{2}$.

Reverse transcription-quantitative polymerase chain reaction $(R T-q P C R)$. Gene expression of TIMP-1, MMP-2, MMP-9, COL I and III, and GAPDH in tissues was evaluated by RT-qPCR. The primers used for amplification were purchased from Beijing SBS Genetech Co., Ltd. (Beijing, China). Following drug treatment, total RNA of HPLFs was isolated using TRIzol ${ }^{\circledR}$ reagent (Invitrogen; Thermo Fisher Scientific, Inc., Waltham, MA, USA) according to the manufacturer's protocol. RNA was reverse transcribed to $\mathrm{cDNA}(\mathrm{n}=3)$ using a RevertAid First Strand cDNA Synthesis kit (cat. no. k1622; Thermo Fisher Scientific, Inc.). Primer sequences for TIMP-1, MMP-2, MMP-9, COL I and III, and GAPDH were purchased from SBS Genetech Co., Ltd. (Table I). qPCR was performed using SYBR ${ }^{\circledR}$ Premix Ex Taq ${ }^{\mathrm{TM}}$ reagent (cat. no. DRR041; Takara Bio, Inc., Otsu, Japan) and an Applied Biosystems 7500 Real-Time system (Applied Biosystems; Thermo Fisher Scientific, Inc.). Normalized threshold (Cq) values were used for comparison (22). Each sample was analyzed in triplicate to ensure accuracy.

MMP zymography assay. Serum-free medium was added to cells following drug treatment, following which they were incubated for $24 \mathrm{~h}$ at $37^{\circ} \mathrm{C}$. The cell supernatant was extracted by centrifugation for $10 \mathrm{~min}$ at $37^{\circ} \mathrm{C}$ and $12,000 \mathrm{x}$ g to detect the activity of MMP-2 and -9 by zymography and proteins were loaded onto acrylamide gels. Quantification of protein was performed using the BCA method. Proteins $(20 \mu \mathrm{g}$ per lane) were separated by $8 \%$ SDS-PAGE containing collagen enzyme substrates to electrophoresis. Subsequently, gels were washed with zymogram renaturing buffer (10X, diluted 1:9 with deionized water) for 30 min and incubated with enzyme 
Table I. Primer sequences for RT-qPCR.

\begin{tabular}{llll}
\hline Gene & Species & \multicolumn{1}{c}{ Forward primer (5'-3') } & \multicolumn{1}{c}{ Reverse primer (5'-3') } \\
\hline GAPDH & Human & GCACCGTCAAGGCTGAGAAC & TGGTGAAGACGCCAGTGGA \\
TIMP-1 & Human & CCAAAGCAGTGAGCGAGA & ACGCTGGTATAAGGTGGTCTG \\
MMP-2 & Human & AGTTTCCATTCCGCTTCCAG & CGGTCGTAGTCCTCAGTGGT \\
MMP-9 & Human & GTCCACCCTTGTGCTCTTCC & GACTCTCCACGCATCTCTGC \\
COL I & Human & CAAGACGAAGACATCCCACCAATC & ACAGATCACGTCATCGCACAACA \\
COL III & Human & TCGCTCTGCTTCATCCCACTAT & CTTCCAGACATCTCTATCCGCAT
\end{tabular}

TIMP-1, tissue inhibitor of metalloproteinase; MMP, matrix metalloproteinase; COL, collagen; RT-qPCR, reverse transcription-quantitative polymerase chain reaction.

reaction buffer for $6 \mathrm{~h}$ at $37^{\circ} \mathrm{C}$, stained by Coomassie Blue R-250 for 30 min, incubated with destaining solution $(100 \%$ methanol:acetic acid:water, 50:10:40) for $30 \mathrm{~min}$ at room temperature and visualized using a YLN-5000 Electrophoretic Optical Density Scanner (cat. no. YLN-26; Beijing Yu Langnuo Technology Co., Ltd., Beijing, China).

Western blot analysis. HPLFs were harvested with RIPA lysis buffer (Wuhan Boster Biological Technology, Ltd., Wuhan, China) containing a protein inhibitor cocktail (Sigma-Aldrich; Merck KGaA.). Protein was extracted by centrifugation for $10 \mathrm{~min}$ at $4^{\circ} \mathrm{C}$ and $12,000 \mathrm{x}$. The protein concentration was quantified using a bicinchoninic acid assay kit (cat. no. P0010; Beyotime Institute of Biotechnology, Haimen, China). Total cellular proteins $(20 \mu \mathrm{g})$ were mixed with 5X gel loading buffer, separated by $10 \%$ SDS-PAGE and transferred onto polyvinylidene fluoride membranes (Merck $\mathrm{KGaA}$ ). Membranes were blocked in $5 \mathrm{~g} / \mathrm{l}$ skimmed milk for $1 \mathrm{~h}$ at room temperature and washed in TBS. Membranes were incubated with the following rabbit primary antibodies: Anti-TIMP-1 (1:2,000; cat. no. ab12684), anti-COL I (1:2,000; cat. no. ab34710) and anti-COL III (1:5,000; cat. no. ab7778), all purchased from Abcam (Cambridge, MA, USA) overnight at $4^{\circ} \mathrm{C}$, followed by incubation with fluorescence-labeled secondary antibodies $\left(1: 20,000\right.$; IRDye ${ }^{\circledR} 800 \mathrm{CW}$ goat anti-rabbit IgG; cat. no. 926-32211; LI-COR Biosciences, Lincoln, NE, USA) for $1 \mathrm{~h}$ at $37^{\circ} \mathrm{C}$ after washing. A rabbit anti-GAPDH primary antibody (1:2,500; cat. no. ab9485; Abcam) served as an internal reference control. The reactive bands were detected with an Odyssey ${ }^{\circledR}$ infrared imaging system (LI-COR Biosciences).

Statistical analysis. Data are presented as the mean \pm standard deviation for each group and were analyzed by one-way analysis of variance using SPSS software version 21.0 (IBM SPSS, Armonk, NY, USA). Differences between two groups were determined using Dunnett's test, and multiple means were compared by Tukey's test. $\mathrm{P}<0.05$ was considered to indicate a statistically significant difference.

\section{Results}

Identification of HPLFs. A previous study of the authors identified stable and accurate HPLFs by positive staining of vimentin and negative staining of cytokeratin (23). They primarily exhibit long spindles connecting to each other to form a network structure with a similar behavior to fibroblasts, as observed by light microscopy.

Puerarin promotes HPLF proliferation. To confirm the effect of puerarin on proliferation of HPLFs, a CCK-8 assay was performed. Increased proliferation was detected in the HPLF culture $24 \mathrm{~h}$ after treatment with puerarin. At 48 and $72 \mathrm{~h}$, proliferation rates further significantly increased. Proliferation rates of HPLFs increased markedly following $0.1 \mathrm{mmol} / 1$ puerarin treatment compared with $1 \mathrm{mmol} / \mathrm{l}$ and $0.01 \mathrm{mmol} / \mathrm{l}$ puerarin at 24, 48 and $72 \mathrm{~h}(\mathrm{P}<0.01$; Fig. 1A). These results indicated that HPLF proliferation was enhanced by puerarin in a time-dependent manner, and all the three concentration of puerarin may promote HPLF proliferation.

Effects of puerarin on HPLFs in pelvic floor tissue of POP patients. The effects of puerarin on TIMP-1, MMP-2, MMP-9 and COL I and III mRNA expression levels in HPLFs derived from pelvic floor tissue of POP patients were tested to investigate its effects on resistance to degradation of the extracellular matrix (ECM). As presented in Fig. 1B, $0.10 \mathrm{mmol} / 1$ puerarin treatment significantly increased mRNA expression levels of TIMP-1 ( $\mathrm{P}<0.05)$, and MMP-2 and -9 mRNA expression levels were significantly decreased following $0.01,0.10$ and $1.00 \mathrm{mmol} / \mathrm{l}$ puerarin treatment $(\mathrm{P}<0.01$; Fig. $1 \mathrm{C})$, compared with the positive control. COL I and III mRNA expression levels were significantly increased following all three concentrations of puerarin $(\mathrm{P}<0.01$; Fig. 1D) compared with the positive control. Therefore, puerarin may regulate the degradation and synthesis of ECM components at the level of transcription. These results suggested that to resist ECM degradation, the most suitable concentration of puerarin is $\sim 0.10 \mathrm{mmol} / 1$.

Varying expressions of POP-associated genes in HPLFs between patients with and without POP. To detect whether the regulatory factors and metabolism of collagens alter in HPLFs between patients with or without POP, RT-qPCR, zymography assay and western blotting were performed to detect levels of TIMP-1, MMP-2, MMP-9, and COL I and III. As collagens are vital elements in pelvic connective tissue to maintain the fastness of ligament, significant decreases in 


\section{A}
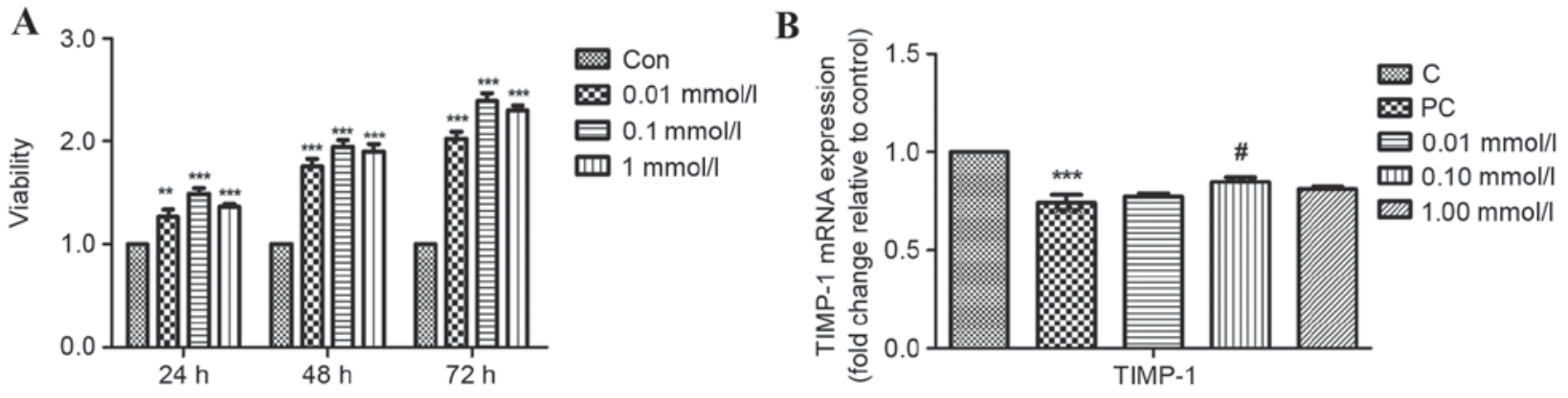

C

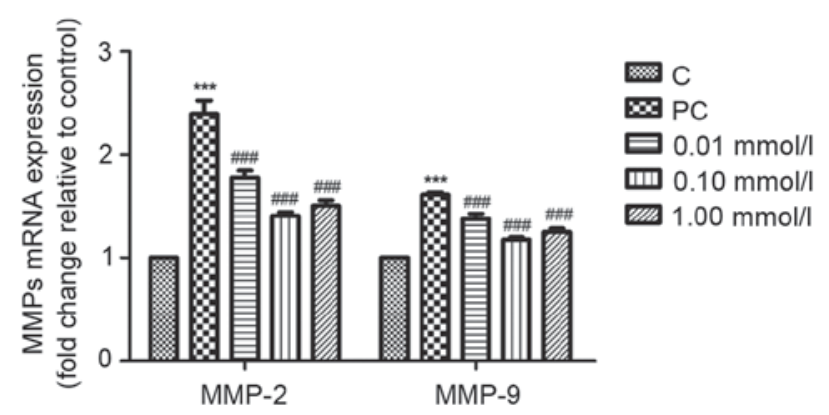

D

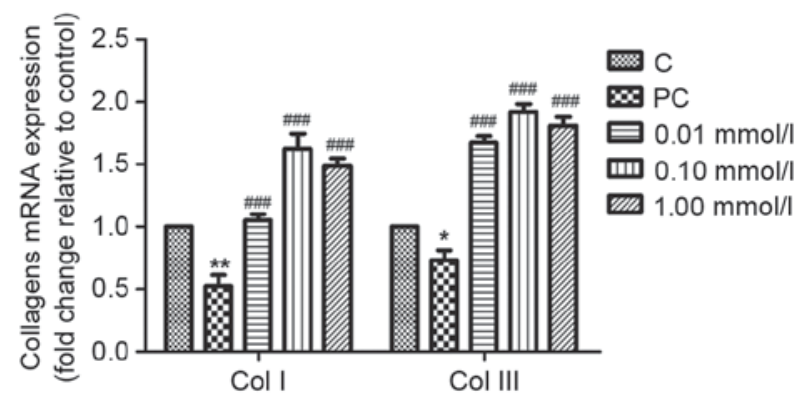

Figure 1. Effects of puerarin treatment on proliferation of HPLFs and mRNA expression of pelvic organ prolapse-associated genes in HPLFs. (A) Following incubation for 24,48 or $72 \mathrm{~h}$ with $0.01,0.10$ or $1.00 \mathrm{mmol} / 1$ puerarin, HPLF viability was assessed by Cell Counting Kit-8 assay. Following incubation for $48 \mathrm{~h}$ with $0.01,0.10$ or 1.00 mmol/1 puerarin, mRNA expression levels of (B) TIMP-1 (C) MMP-2 and -9, and (D) COL I and III were detected by reverse transcription-quantitative polymerase chain reaction. The $\mathrm{C}$ and PC groups were treated with common medium without puerarin. Data are presented as the mean \pm standard deviation $(\mathrm{n}=5)$. ${ }^{*} \mathrm{P}<0.05,{ }^{* *} \mathrm{P}<0.01$ and ${ }^{* * * *} \mathrm{P}<0.001$ vs. $\mathrm{C}$; ${ }^{\#} \mathrm{P}<0.05$ and ${ }^{\# \# "} \mathrm{P}<0.001$ vs. PC. C, control; PC, positive control; HPLF, human parametrial ligament fibroblast; TIMP-1, tissue inhibitor of metalloproteinase-1; MMP, matrix metalloproteinase; COL, collagen.

COL I $(\mathrm{P}<0.01)$ and III $(\mathrm{P}<0.05)$ mRNA expression levels were observed in HPLFs from patients with POP (Fig. 1D). Similarly, as observed on a gelatin gel (Fig. 2A), MMP-2 and -9 (Fig. 2B) activity was inhibited by puerarin treatment at all concentrations compared with the positive control $(\mathrm{P}<0.01)$. Additionally, MMP-2 and MMP-9 protein and mRNA expression levels were increased in the HPLFs of POP patients compared with controls $(\mathrm{P}<0.001)$.

Protein expression levels of TIMP-1, and COL I and II, were additionally detected by western blot analysis (Fig. 3A). COL I (Fig. 3B) and III (Fig. 3C) protein expression levels were significantly decreased in POP patients compared with controls $(\mathrm{P}<0.001$ and $\mathrm{P}<0.05$, respectively); however, 0.01 , 0.10 and $1.00 \mathrm{mmol} / \mathrm{l}$ puerarin treatment significantly reversed this effect. As presented in Fig. 3D, protein expression levels of TIMP-1 were markedly decreased in HPLFs of POP patients compared with controls $(\mathrm{P}<0.001)$.

ECM remodeling is a vital factor in the development of POP. These results demonstrated that MMP-2 and -9 transcription was upregulated, whereas TIMP-1, and COL I and III expression levels were downregulated in POP patients. Furthermore, the activity of MMPs was increased in POP patients, indicating more collagen degradation than collagen synthesis.

\section{Discussion}

Fibroblasts deposit ECM components, including elastic fibers and collagen, to maintain tissue elasticity and toughness of connective tissue $(24,25)$. It has previously been demonstrated that abnormalities with intrinsic connective tissue composed of fibroblasts are associated with the development of POP (10). Fibroblasts serve a pivotal role, particularly in pelvic connective tissue, in ECM remodeling and mechanical force resisting by regulating the balance between collagen synthesis and degradation following tissue injury $(26,27)$, and fibroblasts exhibit different functional characteristics in the vaginal tissue of women with POP compared with women without POP (28). Even within a single tissue, fibroblasts exhibit remarkable functional diversity. Therefore, once the integrity and function of fibroblasts are destroyed by factors including pregnancy, childbirth and dystocia, the risk of POP markedly increases $(1,29,30)$.

Histologically, POP is characterized by degradation of fibroblasts and an imbalance between deposition and degradation of the ECM (31). Tissue remodeling is closely associated to modifications in cell proliferation, differentiation, ECM expression and the release of signaling molecules (32). The overexpression of MMPs or underexpression of TIMPs may disrupt the dynamic balance of the ECM. MMPs are able to cleave almost all ECM components, mediating pelvic tissue remodeling in health and disease $(33,34)$, and can degrade collagen and other ECM proteins. Elevated levels of TIMPs have a potent inhibitory effect on MMP activation (35). During ECM remodeling, the balance between MMPs and their inhibitors, TIMPs, is as important as appropriate production of the ECM, which is regulated by numerous cytokines and growth factors (36). The activity of MMPs is balanced by TIMPs (37), and the binding of TIMPs to inactive MMPs inhibits the proteolytic activity and accordingly limits ECM degradation. Thus, TIMP-1 controls the activity of MMPs 
A

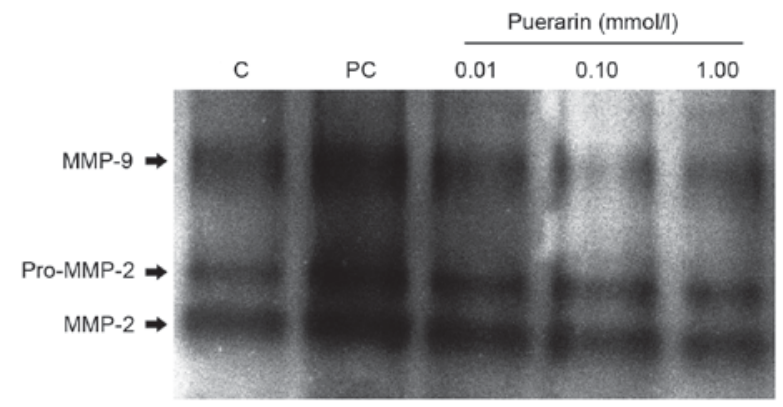

B
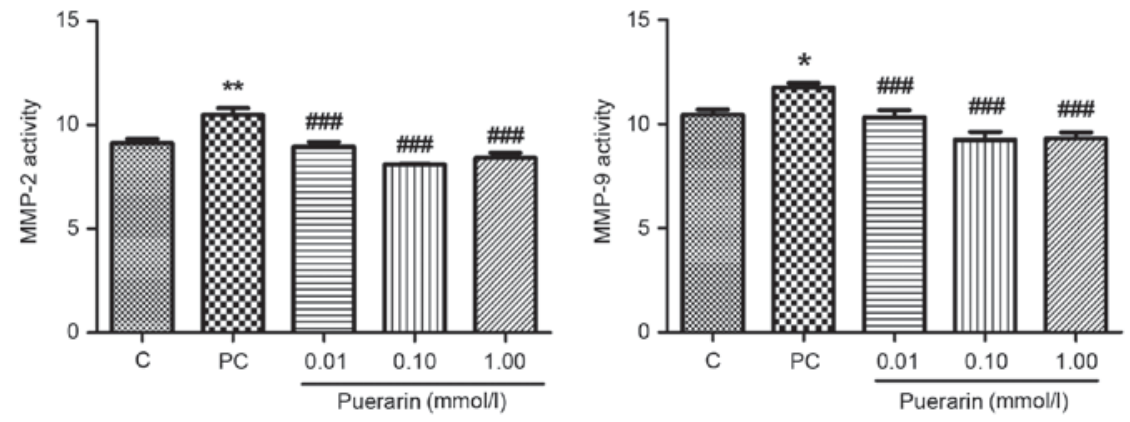

Figure 2. Effects of puerarin treatment on MMP-2 and -9. Following treatment with $0.01,0.10$ or $1.00 \mathrm{mmol} / 1$ puerarin for $48 \mathrm{~h}$, the protein expression levels of MMP-2 and MMP-9 secreted by HPLFs were detected by gelatin zymography assay. (A) Representative gelatin gel image and (B) quantification of MMP-2 and -9 expression levels, demonstrating that puerarin treatment inhibited their activities. Data are presented as the mean \pm standard deviation $(\mathrm{n}=5)$. ${ }^{*} \mathrm{P}<0.05$,

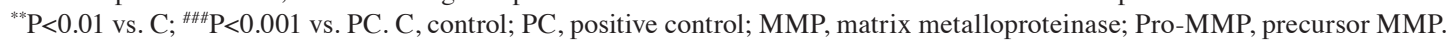

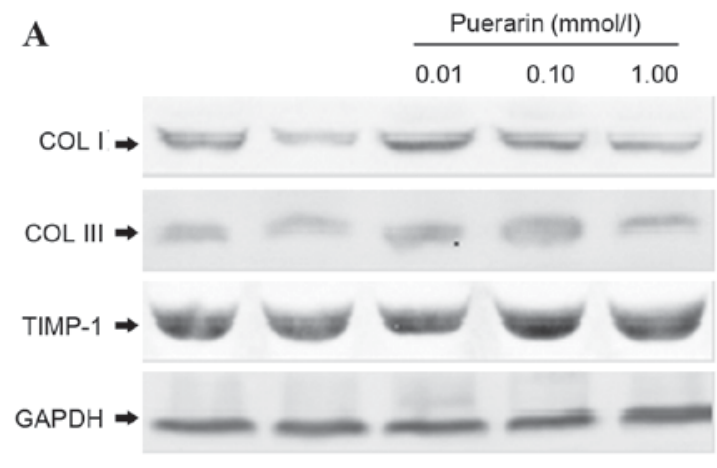

C

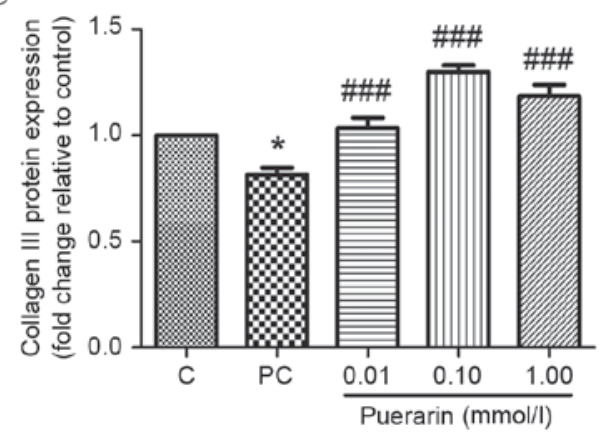

B

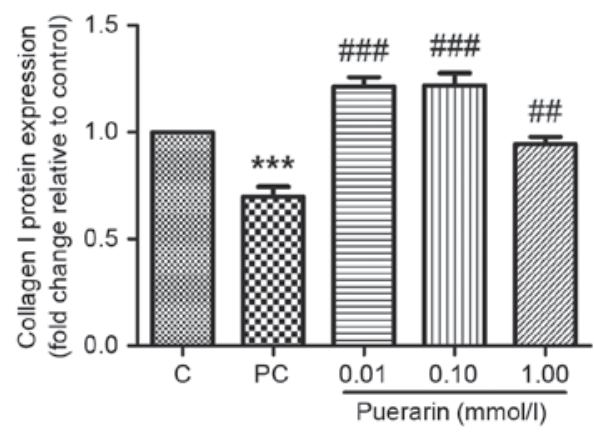

D

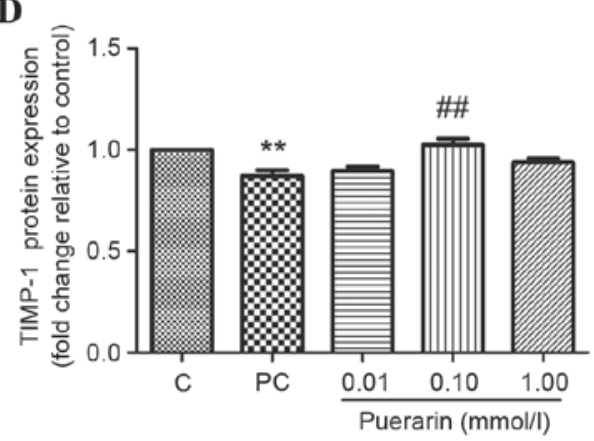

Figure 3. Effects of puerarin treatment on expression of pelvic organ prolapse-associated proteins in human parametrial ligament fibroblasts. (A) Representative western blot images and quantification of (B) COL I, (C) COL III and (D) TIMP-1 protein expression levels. GAPDH served as an internal control. Data are presented as the mean \pm standard deviation $(\mathrm{n}=5)$. ${ }^{*} \mathrm{P}<0.05,{ }^{* * *} \mathrm{P}<0.01$ and ${ }^{* * *} \mathrm{P}<0.001$ vs. $\mathrm{C}$; ${ }^{\# \#} \mathrm{P}<0.01$ and ${ }^{\# \# \#} \mathrm{P}<0.001$ vs. $\mathrm{PC}$. C, control; $\mathrm{PC}$, positive control; COL, collagen; TIMP-1, tissue inhibitor of metalloproteinase.

and appears to be an important regulator of ECM production $(38,39)$. Furthermore, the primary collagens in pelvic tissue, COL I and II, provide powerful tension and strength for pelvic tissue. However, MMPs impact the tension and 
resilience of pelvic tissue by regulating the metabolism of COL I and II. Therefore, the present study selected to examine these interrelated factors.

Secretion and remodeling of the ECM are important functions of fibroblasts. The present study demonstrated that ECM metabolism and associated metabolism molecules including TIMP-1, MMPs and collagens, were altered in HPLFs of POP patients compared with controls. Other research groups assessing collagen content in pelvic floor connective tissue additionally concluded that total collagen content is decreased in the pelvic floor connective tissue of women with POP in comparison with asymptomatic controls $(40,41)$. Loss of the ECM leads to dysfunction of attachment and support of pelvic connective tissue (31). Thus, it was hypothesized the excessive degradation of collagen may result from decrease of the TIMP:MMP ratio in pelvic floor tissues, as previously reported by Lin et al (42). It has been demonstrated that abnormality of the COL III and MMP-2 signaling pathway contributes to weakness of connective tissues of patients with POP (43). The metabolism of COL I and III depends on the activity of the interstitial MMPs including gelatinases, MMP-2 and MMP-9. In POP, it has been consistently demonstrated that the expression of MMP-2 is increased in uterosacral ligaments, and may be involved in altering collagen metabolism $(44,45)$. Furthermore, TIMP-1 may regulate cellular processes including cell growth, apoptosis and differentiation, and may serve a role in urethral scar formation independent of its metalloproteinase inhibitory activity $(38,46)$. At the genetic level, the TIMP-1 protein is encoded from six exons that may be functionally defined as an $\mathrm{N}$-terminal domain (amino acids 1 to 126) that is sufficient to retain its inhibitory function of MMPs (47). Furthermore, MMP-2 and -9, known as gelatinases, are key enzymes resulting in weak ductility and lack of integrity in the collagen tissues (48). In addition, increased MMP-2 or -9: TIMP-1 ratios downregulate COL I and III levels, mediating the development of POP (49). Therefore, TIMP-1, and MMP-2 and -9 were selected for examination in the present study. As a primary active ingredient extracted from a Kudzu root, puerarin was demonstrated to protect against degradation of collagen. Furthermore, the ratio of TIMP-1: MMP-2 and -9 was increased by puerarin treatment. The present study demonstrated that the expression of MMPs, which are closely associated with ECM degradation, is regulated at the transcriptional level by growth factors and transcriptional factors, and its activity may additionally be inhibited by TIMPs following its secretion. Therefore, upstream regulators of MMPs may be involved in this process.

TIMP-1 has been the most extensively studied of the four reported TIMPs, which has been demonstrated to inhibit MMP activity by forming 1:1 stoichiometric non-covalent complexes with endopeptidase. Consequently, TIMP-1 serves a vital role in maintaining the balance between ECM accumulation and degradation in various physiological processes (50). Thus, the activity of MMPs may be regulated at transcriptional and protein levels to maintain ECM stability. Although the underlying mechanisms of POP remain unclear, degradation of the ECM may be involved $(51,52)$. The present study demonstrated that puerarin treatment, particularly $0.10 \mathrm{mmol} / \mathrm{l}$, enhances TIMP-1, and COL-I and III expression levels in HPLFs, and inhibits the activity of MMP-2 and -9, strongly supporting the effects of puerarin in preventing ECM degradation.
In conclusion, the present study provided evidence for increased ECM degradation in the pelvic tissue of patients with POP compared with healthy controls. Furthermore, puerarin, an isoflavonoid, exhibited a protective effect against POP via its anti-degradation effects on collagens, implicating puerarin as a potential effective therapeutic agent for the treatment of POP. Further research, including animal experiments, is required to validate these findings.

\section{Acknowledgements}

The present study was supported by the National Natural Science Foundation of China (grant no. 81471442) and the Foundation of Collaborative and Innovation Projects of Wuhan University School of Medicine (grant no. 523266078).

\section{References}

1. Swift S, Woodman P, O'Boyle A, Kahn M, Valley M, Bland D, Wang W and Schaffer J: Pelvic organ support study (POSST): The distribution, clinical definition and epidemiologic condition of pelvic organ support defects. Am J Obstet Gynecol 192: 795-806, 2005

2. Mallett VT: Female urinary incontinence: What the epidemiologic data tell us. Int J Fertil Womens Med 50: 12-17, 2005.

3. Wong KH,Li GQ, Li KM, Razmovski-Naumovski V and Chan K: Kudzu root: Traditional uses and potential medicinal benefits in diabetes and cardiovascular diseases. J Ethnopharmacol 134: 584-607, 2011.

4. Zhang J, Guo W, Tian B, Sun M, Li H, Zhou L and Liu X: Puerarin attenuates cognitive dysfunction and oxidative stress in vascular dementia rats induced by chronic ischemia. Int J Clin Exp Pathol 8: 4695-4704, 2015.

5. Hsu FL, Liu IM, Kuo DH, Chen WC, Su HC and Cheng JT: Antihyperglycemic effect of puerarin in streptozotocin-induced diabetic rats. J Nat Prod 66: 788-792, 2003.

6. Gao LN, Zhou X, Zhang Y, Cui YL, Yu CQ and Gao S: The anti-inflammatory activities of ethanol extract from dan-lou prescription in vivo and in vitro. BMC Complement Altern Med 15: 317, 2015.

7. Wang C, Meng MX, Tang XL, Chen KM, Zhang L, Liu WN and Zhao YY: The proliferation, differentiation and mineralization effects of puerarin on osteoblasts in vitro. Chin J Nat Med 12: 436-442, 2014.

8. Rizk DE, Hassan HA, Al-Marzouqi AH, Ramadan GA, Al-Kedrah SS, Daoud SA and Fahim MA: Combined estrogen and ghrelin administration restores number of blood vessels and collagen type I/III ratio in the urethral and anal canal submucosa of old ovariectomized rats. Int Urogynecol J Pelvic Floor Dysfunct 19: 547-552, 2008.

9. Ewies AA, Elshafie M, Li J, Stanley A, Thompson J, Styles J, White I and Al-Azzawi F: Changes in transcription profile and cytoskeleton morphology in pelvic ligament fibroblasts in response to stretch: The effects of estradiol and levormeloxifene. Mol Hum Reprod 14: 127-135, 2008.

10. Bai SW, Choe BH, Kim JY and Park KH: Pelvic organ prolapse and connective tissue abnormalities in Korean women. J Reprod Med 47: 231-234, 2002.

11. Connell KA, Guess MK, Chen H, Andikyan V, Bercik R and Taylor HS: HOXA11 is critical for development and maintenance of uterosacral ligaments and deficient in pelvic prolapse. J Clin Invest 118: 1050-1055, 2008.

12. Wang X, Wu J, Chiba H, Umegaki K, Yamada K and Ishimi Y: Puerariae radix prevents bone loss in ovariectomized mice. J Bone Miner Metab 21: 268-275, 2003.

13. Kim KM, Jung DH, Jang DS, Kim YS, Kim JM, Kim HN, Surh YJ and Kim JS: Puerarin suppresses AGEs-induced inflammation in mouse mesangial cells: A possible pathway through the induction of heme oxygenase-1 expression. Toxicol Appl Pharmacol 244: 106-113, 2010.

14. Strinic T, Vulic M, Tomic S, Capkun V, Stipic I and Alujevic I: Increased expression of matrix metalloproteinase-1 in uterosacral ligament tissue from women with pelvic organ prolapse. Acta Obstet Gynecol Scand 89: 832-834, 2010. 
15. Yang X, Zhang H, Wang J, Zhang Z and Li C: Puerarin decreases bone loss and collagen destruction in rats with ligature-induced periodontitis. J Periodontal Res 50: 748-757, 2015.

16. Wang D, Liu Y, Han J, Zai D, Ji M, Cheng W, Xu L, Yang L, $\mathrm{He} \mathrm{M}$, Ni J, et al: Puerarin suppresses invasion and vascularization of endometriosis tissue stimulated by $17 \beta$-estradiol. PLoS One 6: e25011, 2011.

17. Zhang S, Chen S, Shen Y, Yang D, Liu X, Sun-Chi AC and $\mathrm{Xu} \mathrm{H}$ : Puerarin induces angiogenesis in myocardium of rat with myocardial infarction. Biol Pharm Bull 29: 945-950, 2006.

18. Tian F, Xu LH, Zhao W, Tian LJ and Ji XL: The neuroprotective mechanism of puerarin treatment of acute spinal cord injury in rats. Neurosci Lett 543: 64-68, 2013.

19. Zhang MY, Qiang H, Yang HQ, Dang XQ and Wang KZ: In vitro and in vivo effects of puerarin on promotion of osteoblast bone formation. Chin J Integr Med 18: 276-282, 2012.

20. Zhu JH, Wang XX, Chen JZ, Shang YP, Zhu JH, Guo XG and Sun J: Effects of puerarin on number and activity of endothelial progenitor cells from peripheral blood. Acta Pharmacol Sin 25 1045-1051, 2004

21. Zhang Y, Zeng X, Zhang L and Zheng X: Stimulatory effect of puerarin on bone formation through activation of PI3K/Akt pathway in rat calvaria osteoblasts. Planta Med 73: 341-347, 2007.

22. Livak KJ and Schmittgen TD: Analysis of relative gene expression data using real-time quantitative PCR and the 2(-Delta Delta C(T)) method. Methods 25: 402-408, 2001.

23. Hong S, Li H, Wu D, Li B, Liu C, Guo W, Min J, Hu M, Zhao Y andf Yang Q: Oxidative damage to human parametrial ligament fibroblasts induced by mechanical stress. Mol Med Rep 12: $5342-5348,2015$

24. Watt FM and Fujiwara H: Cell-extracellular matrix interactions in normal and diseased skin. Cold Spring Harb Perspect Biol 3 : a005124, 2011.

25. Parsonage G, Filer AD, Haworth O, Nash GB, Rainger GE, Salmon M and Buckley CD: A stromal address code defined by fibroblasts. Trends Immunol 26: 150-156, 2005.

26. Gao E, Lei YH, Shang X, Huang ZM, Zuo L, Boucher M, Fan Q Chuprun JK, Ma XL and Koch WJ: A novel and efficient model of coronary artery ligation and myocardial infarction in the mouse. Circ Res 107: 1445-1453, 2010.

27. Sassoli C, Chellini F, Pini A, Tani A, Nistri S, Nosi D, Zecchi-Orlandini S, Bani D and Formigli L: Relaxin prevents cardiac fibroblast-myofibroblast transition via notch-1-mediated inhibition of TGF- $\beta /$ Smad3 signaling. PLoS One 8: e63896, 2013

28. Kufaishi H, Alarab M, Drutz H, Lye S and Shynlova O Comparative characterization of vaginal cells derived from premenopausal women with and without severe pelvic organ prolapse. Reprod Sci 23: 931-943, 2016.

29. Mant J, Painter R and Vessey M: Epidemiology of genital prolapse: Observations from the oxford family planning association study. Br J Obstet Gynaecol 104: 579-585, 1997.

30. Swift SE, Tate SB and Nicholas J: Correlation of symptoms with degree of pelvic organ support in a general population of women: What is pelvic organ prolapse? Am J Obstet Gynecol 189: 372-379, 2003

31. Budatha M, Roshanravan S, Zheng Q, Weislander C, Chapman SL, Davis EC, Starcher B, Word RA and Yanagisawa $\mathrm{H}$ : Extracellular matrix proteases contribute to progression of pelvic organ prolapse in mice and humans. J Clin Invest 121: 2048-2059, 2011

32. Proff $P$ and Romer P: The molecular mechanism behind bone remodelling: A review. Clin Oral Investig 13: 355-362, 2009.

33. Ruiz-Zapata AM, Kerkhof MH, Zandieh-Doulabi B, Brolmann HA, Smit TH and Helder MN: Functional characteristics of vaginal fibroblastic cells from premenopausal women with pelvic organ prolapse. Mol Hum Reprod 20: 1135-1143, 2014.

34. Wang X, Li Y, Chen J, Guo X, Guan H and Li C: Differential expression profiling of matrix metalloproteinases and tissue inhibitors of metalloproteinases in females with or without pelvic organ prolapse. Mol Med Rep 10: 2004-2008, 2014
35. Page-McCaw A, Ewald AJ and Werb Z: Matrix metalloproteinases and the regulation of tissue remodelling. Nat Rev Mol Cell Biol 8: 221-233, 2007.

36. Lu KV, Jong KA, Rajasekaran AK, Cloughesy TF and Mischel PS: Upregulation of tissue inhibitor of metalloproteinases (TIMP)-2 promotes matrix metalloproteinase (MMP)-2 activation and cell invasion in a human glioblastoma cell line. Lab Invest 84: 8-20, 2004.

37. Gaultier F, Foucault-Bertaud A, Lamy E, Ejeil AL, Dridi SM, Piccardi N, Piccirilli A, Msika P, Godeau G and Gogly B: Effects of a vegetable extract from Lupinus albus (LU105) on the production of matrix metalloproteinases (MMP1, MMP2, MMP9) and tissue inhibitor of metalloproteinases (TIMP1, TIMP2) by human gingival fibroblasts in culture. Clin Oral Investig 7: 198-205, 2003.

38. Ries C: Cytokine functions of TIMP-1. Cell Mol Life Sci 71: 659-672, 2014.

39. Arthur MJ and Iredale JP: Hepatic lipocytes, TIMP-1 and liver fibrosis. J R Coll Physicians Lond 28: 200-208, 1994.

40. Chen BH, Wen Y, Li H and Polan ML: Collagen metabolism and turnover in women with stress urinary incontinence and pelvic prolapse. Int Urogynecol J Pelvic Floor Dysfunct 13: 80-87, 2002.

41. Kannan K, McConnell A, McLeod M and Rane A: Microscopic alterations of vaginal tissue in women with pelvic organ prolapse. J Obstet Gynaecol 31: 250-253, 2011.

42. Lin SY, Tee YT, Ng SC, Chang H, Lin P and Chen GD: Changes in the extracellular matrix in the anterior vagina of women with or without prolapse. Int Urogynecol J Pelvic Floor Dysfunct 18: 43-48, 2007.

43. Ma Y, Guess M, Datar A, Hennessey A, Cardenas I, Johnson J and Connell KA: Knockdown of Hoxa11 in vivo in the uterosacral ligament and uterus of mice results in altered collagen and matrix metalloproteinase activity. Biol Reprod 86: 100, 2012.

44. Phillips $\mathrm{CH}$, Anthony F, Benyon $\mathrm{C}$ and Monga AK: Collagen metabolism in the uterosacral ligaments and vaginal skin of women with uterine prolapse. BJOG 113: 39-46, 2006.

45. Gabriel B, Watermann D, Hancke K, Gitsch G, Werner M, Tempfer $\mathrm{C}$ and zur Hausen A: Increased expression of matrix metalloproteinase 2 in uterosacral ligaments is associated with pelvic organ prolapse. Int Urogynecol J Pelvic Floor Dysfunct 17: 478-482, 2006

46. Li C, Xu YM and Li HB: Preliminary experimental study of urethral reconstruction with tissue engineering and RNA interference techniques. Asian J Androl 15: 430-433, 2013.

47. Murphy G, Houbrechts A, Cockett MI, Williamson RA, O'Shea M and Docherty AJ: The N-terminal domain of tissue inhibitor of metalloproteinases retains metalloproteinase inhibitory activity. Biochemistry 30: 8097-8102, 1991.

48. Amalinei C, Caruntu ID, Giuşcă SE and Balan RA: Matrix metalloproteinases involvement in pathologic conditions. Rom J Morphol Embryol 51: 215-228, 2010.

49. Jackson SR, Avery NC, Tarlton JF, Eckford SD, Abrams P and Bailey AJ: Changes in metabolism of collagen in genitourinary prolapse. Lancet 347: 1658-1661, 1996.

50. Batra J, Robinson J, Soares AS, Fields AP, Radisky DC and Radisky ES: Matrix metalloproteinase-10 (MMP-10) interaction with tissue inhibitors of metalloproteinases TIMP-1 and TIMP-2: Binding studies and crystal structure. J Biol Chem 287: 15935-15946, 2012.

51. Alarab M, Kufaishi H, Lye S, Drutz H and Shynlova O: Expression of extracellular matrix-remodeling proteins is altered in vaginal tissue of premenopausal women with severe pelvic organ prolapse. Reprod Sci 21: 704-715, 2014.

52. Goepel C, Johanna Kantelhardt E, Karbe I, Stoerer S and Dittmer J: Changes of glycoprotein and collagen immunolocalization in the uterine artery wall of postmenopausal women with and without pelvic organ prolapse. Acta Histochem 113: 375-381, 2011. 